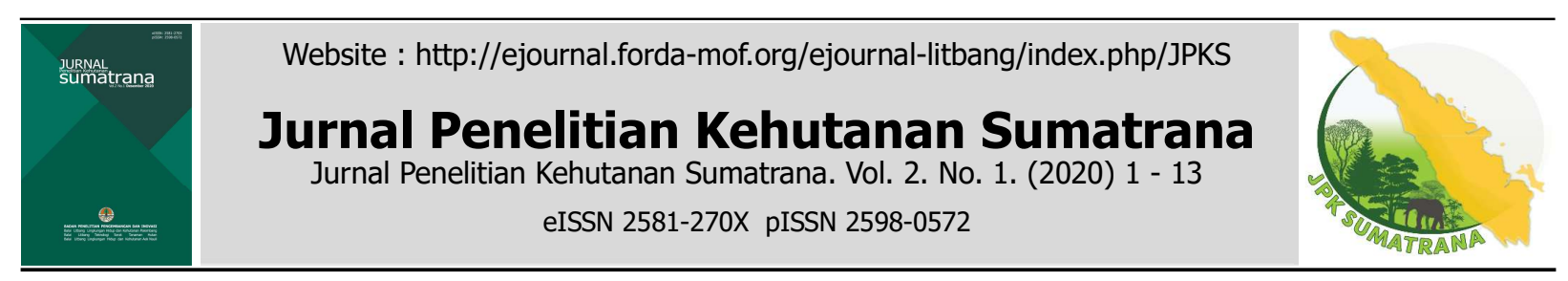

\title{
Pemetaan Permasalahan Kebakaran Hutan dan Lahan Kasus di Provinsi Riau
}

\section{(The Mapping of Forest and Land Fire Problems
Case in Riau Province)}

\author{
Andhika Silva Yunianto ${ }^{1 *}$
}

${ }^{1}$ Balai Litbang Teknologi Serat Tanaman Hutan

Jl. Raya Bangkinang - Kuok Km. 9 PO BOX 4/BKN Bangkinang 28401

*Email: Andhikasilva@gmail.com

\section{Article History:}

Received 20 Agust 2019; Received in revised form 26 November 2019; Accepted 28 December 2020; Available online since 31 December 2020

\begin{abstract}
ABSTRAK
Kebakaran hutan dan lahan di Riau selalu berulang setiap memasuki musim kemarau. Kebakaran hutan dan lahan tahun 2015 merupakan kejadian terbesar, berdasarkan lokasi kejadian 75 persen terjadi di lahan gambut. Hampir 99 persen kejadian kebakaran hutan dan lahan merupakan ulah manusia, dimana sekitar 80 persen lahan yang terbakar kemudian berubah menjadi lahan perkebunan. Tujuan dari penelitian ini adalah untuk memetakan kejadian kebakaran hutan dan lahan tahun 2010-2015 berdasarkan areal pemanfaatan, pembangunan wilayah dan politik lokal, serta menganalisis faktor pemicu yang menjadi penyebab kebakaran hutan dan lahan di Riau. Analisis dilakukan menggunakan pendekatan deskriptif kualitatif berdasarkan hasil wawancara mendalam untuk mengetahui aktivitas/perilaku masyarakat yang mempengaruhi terjadinya kebakaran hutan dan lahan. Untuk menghasilkan peta dan mengetahui persebaran kebakaran hutan dan lahan dilakukan dengan menggunakan GIS (Geographic Information System). Analisis peta menunjukkan titik panas (hotspot) banyak ditemukan pada kawasan konsesi IUPHHK-HTI (Izin Usaha Pemanfaatan Hasil Hutan Kayu - Hutan Tanaman Industri). Temuan tersebut menunjukkan adanya keterkaitan antara kebakaran hutan dan lahan dengan konflik antara masyarakat dengan perusahaan dilihat dari areal pemanfaatan, pembangunan wilayah dan politik lokal. Pada akhirnya, pemerintah perlu meningkatkan kewaspadaan tinggi terhadap kebakaran hutan dan lahan di areal yang berpotensi terjadi konflik pemanfaatan kawasan hutan antara masyarakat dengan perusahaan seperti di areal izin konsesi IUPHHK-HTI. Kewaspadaan perlu dilakukan dengan memperjelas status kawasan dengan memberikan kepastian hukum suatu kawasan melalui pengukuhan kawasan hutan agar legal dan legitimate.
\end{abstract}

Kata Kunci: Pemetaan, kebakaran hutan dan lahan, konflik, politik, okupansi

\begin{abstract}
ABSTRAK
Forest and land fires is a recurring event that always happen in every dry season in Riau Province. Forest and land fires in 2015 was the biggest incident, based on the location 75 percent occurred on peatlands. Almost 99 percent of forest and land fires are human actions effects, about 80 percent of the burned land turns into plantation land. The objective of this study is to mapping the incidence of forest and land fires in 2010-2015 based on utilization area, regional development and local politics, as well as to analyzing the trigger factors of forest and land fires in Riau Province. The analysis was carried out using descriptive qualitative data obtained from in-depth interviews to determine community activities/behaviors which can influence forest and land fires, added by other supporting data. To create a map and find out the distribution of forest and land fires, the study was conducted by using Geographic Information System. Map analysis revealed that many hotspots found in IUPHHK-HTI (Forest Plantation) concession ("Areal Penggunaan Lain"). Those founds showed that there was a link between forest \& land fires and conflict
\end{abstract}


between communities and companies from the utilization area, regional development and local politics. In the end, the government needs to pay special attention by increasing awareness about forest and land fires especially in the areas where there is any potential for conflict over forest use between communities and companies such as in the IUPHHK-HTI concession area. Attention needs to be done by clearing the regional status by providing legal certainty through strengthening the forest area to be legal and legitimate.

Keyword: Mapping, forest and land fires, conflict, political, occupancy

\section{PENDAHULUAN}

Kebakaran hutan dan lahan di Riau merupakan kejadian yang selalu berulang setiap memasuki musim kemarau. Menurut data kejadian kebakaran yang terjadi selama ini, kebakaran hutan dan lahan tahun 2015 merupakan kebakaran hutan dan lahan yang terbesar yang menyebabkan kerugian lebih dari 20 triliyun rupiah (BBCNews.com, 2015). Kebakaran hutan dan lahan tersebut mencapai 52 persen dari total kejadian kebakaran hutan dan lahan yang terjadi secara nasional. Kebakaran tersebut terjadi di Kabupaten Bengkalis, Rokan Hilir, Pelalawan dan Siak. Berdasarkan lokasi kejadian, hampir 75 persen kebakaran hutan dan lahan terjadi di lahan gambut. Kebakaran di lahan gambut ini menjadi penyumbang terbesar kejadian kebakaran karena karakteristik fisik gambut yang mudah terbakar dan lebih sulit dipadamkan dibandingkan dengan kebakaran hutan dan lahan pada lokasi areal lain.

Kebakaran hutan dan lahan secara umum disebabkan oleh 2 (dua) faktor utama, yaitu faktor alam dan faktor manusia. Kejadian kebakaran hutan dan lahan yang dominan disebabkan oleh faktor manusia. Menurut BNPB di tahun 2019, total 99 persen kejadian kebakaran hutan dan lahan merupakan ulah manusia, sekitar 80 persen lahan yang terbakar kemudian berubah menjadi lahan perkebunan (Purnamasari, 2019). Kebakaran hutan dan lahan paling besar dilakukan oleh korporasi sebagaimana diungkapkan oleh KLHK yang menolak menyebutkan data korporasi pembakar hutan (Setyawan, 2019).

Kejadian kebakaran hutan dan lahan memiliki hubungan erat dengan konflik pemanfaatan kawasan hutan, baik pemanfaatan secara legal maupun secara ilegal. Konflik sosial yang terjadi di sektor kehutanan bersifat multidimensional. Artinya, konflik bisa terjadi secara horizontal (antar tingkat grassroot) dan vertikal (konflik terjadi antar kelas sosial), dan konflik sosial ini merupakan inti dari permasalahan sosiologis kehutanan di Indonesia. Konflik di sektor kehutanan melibatkan berbagai pihak mulai dari skala nasional bahkan internasional. Perbedaan status antara pihak yang "kuat" dan yang "lemah" sangat menonjol. Pihak yang "kuat" biasanya akan dengan mudah mempertahankan posisinya karena memiliki kekuatan untuk melawan pihak yang lebih "lemah". Pihak yang "kuat" memiliki informasi yang lebih banyak dan kemampuan finansial yang lebih besar dibandingkan dengan pihak yang "lemah". Bambang Hero Saharjo, Guru Besar IPB mengatakan, konflik pemanfaatan sumberdaya hutan yang terjadi di Riau mayoritas berupa konflik tenurial antara pemegang izin konsesi kehutanan dengan perkebunan masyarakat. Masyarakat merasa bahwa lahan konsesi korporasi merupakan lahan milik masyarakat yang sudah mereka kelola secara turun temurun (Baqiroh, 2019). Perbedaan kekuatan ini menyebabkan rumitnya penyelesaian konflik di sektor kehutanan ditambah faktor letak wilayah terjadinya konflik yang umumnya daerah terpencil (Wulan et al., 2004).

Beberapa penyebab kebakaran hutan dan lahan telah banyak disimpulkan, perhatian terus ditingkatkan dan berbagai tindakan telah diupayakan untuk menghindari, mengurangi serta menekan kejadian kebakaran hutan dan lahan, namun sampai saat ini masih juga terjadi kebakaran hutan dan lahan. Sebagian besar penelitian masih terfokus pada teknis kebakaran hutan dan lahan, hanya sedikit yang membahas terkait dengan kelembagaannya. Penelitian ini bertujuan 
untuk : a) memetakan kejadian kebakaran hutan dan lahan selama tahun 2010-2015 berdasarkan fungsi kawasan, pembangunan wilayah dan politik lokal; dan b) mengetahui faktor-faktor pemicu yang menjadi penyebab kebakaran hutan dan lahan di Provinsi Riau.

\section{METODE PENELITIAN}

Kegiatan ini dilaksanakan pada tahun 2015 dengan mengambil lokasi di Kabupaten Kampar, Kabupaten Pelalawan, Kabupaten Rokan Hilir, Kabupaten Siak, Kabupaten
Bengkalis dan Kabupaten Kepulauan Meranti (Gambar 1). Pemilihan lokasi dilakukan melalui teknik purposive sampling dengan kriteria desa yang menjadi lokasi langganan terjadinya bencana kebakaran hutan dan lahan, serta sering terjadi konflik pemanfaatan kawasan hutan. Pemetaan kebakaran hutan dan lahan dilakukan dalam unit kabupaten. Sedangkan survey dan observasi lapangan dilakukan dalam unit Desa dengan mengambil sampel sebanyak 1 (satu) desa di tiap kabupaten.

Penelitian ini merupakan penelitian

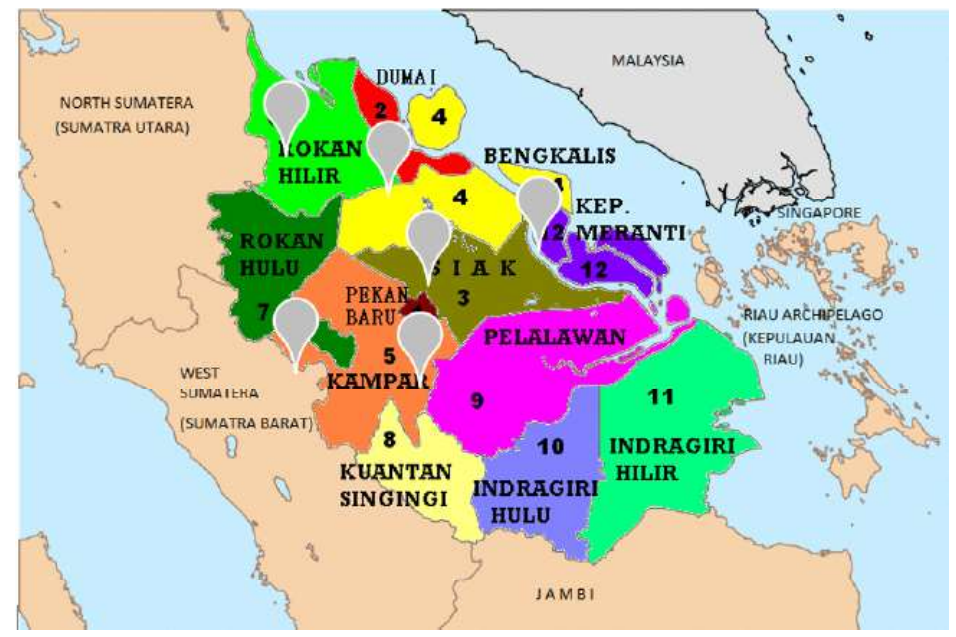

Gambar 1. Lokasi kegiatan pengambilan data

Figure 1. Location of data collection

deskriptif kualitatif dengan metode studi kasus. Data yang digunakan merupakan data primer dan data sekunder. Data primer yang dikumpulkanterkait dengan akarpermasalahan terjadinya konflik lahan yang pada ujungnya mengakibatkan kebakaran hutan dan lahan. Data primer tersebut diperoleh dengan metode observasi lapangan dan wawancara mendalam (indepth interview). Observasi lapangan dilakukan untuk mendapatkan gambaran secara umum mengenai lokasi penelitian. Sementara itu, wawancara mendalam dilakukan untuk mengetahui aktivitas/perilaku masyarakat yang mempengaruhi terjadinya kebakaran hutan dan lahan. Wawancara mendalam dilakukan dengan menggunakan teknik bola salju (snowball sampling) sehingga diperoleh 30 orang narasumber kunci (key informan) yang memiliki peran dan fungsi dalam kejadian kebakaran hutan dan lahan yaitu masyarakat, perangkat desa, perusahaan, dan dari unsur pemerintahan. Peran dan fungsi yang dimaksud adalah pihak-pihak yang diindikasikan terlibat secara langsung ataupun tidak langsung dalam konflik pemanfaatan sumberdaya hutan dan kebakaran hutan dan lahan.

Data sekunder yang digunakan terkait dengan kejadian kebakaran hutan dan lahan dalam kurun waktu 5 tahun terakhir, data koordinat persebaran hotspot kebakaran hutan dan lahan dengan tingkat kepercayaan di atas $80 \%$. Data sekunder tersebut diperoleh melalui kajian literatur dan penelusuran pustaka. Dokumen utama yang digunakan adalah laporan dari instansi pemerintah terkait seperti Manggala Agni dan Kementerian Lingkungan Hidup dan Kehutanan untuk memperoleh data kebakaran hutan dan lahan. 
Sementara itu, untuk menghasilkan petapeta kebakaran sesuai dengan tema yang dimunculkan (wilayah administrasi, jenis tanah, tutupan lahan dan fungsi kawasan) dilakukan pengolahan Geographic Information System (GIS) dengan metode tumpang susun/ overlay data-data spasial terkait. Pengolahan GIS dilakukan dengan bantuan aplikasi Arc. GIS 10.0 yang menggunakan data spasial resmi yang diperoleh dari instansi Pemerintah terkait antara lain data kawasan hutan provinsi Riau, wilayah administrasi, jenis tanah dan tutupan lahan. Untuk melihat perkembangan/ perubahan jumlah titik hotspot kebakaran hutan dan lahan, digunakan data series hasil citra satelit Modis/Terra Aqua. Penggunaan citra satelit Modis/Terra Aqua dirasakan tepat dikarenakan update pembaharuan data dari citra ini relatif sangat cepat yaitu seminggu sekali. Metode analisis data yang digunakan adalah metode analisis deskriptif kualitatif. Analisis deskriptif kualitatif adalah analisis penjelasan untuk data yang bersifat deskriptif.

\section{HASIL DAN PEMBAHASAN}

\section{A. Pemetaan Kejadian Kebakaran Hutan dan Lahan di Riau \\ - Sebaran Kebakaran Hutan dan Lahan}

Kebakaran hutan dan lahan yang terjadi di Riau selama tahun 2010 - 2015 ini memiliki karakteristik yang khas apabila dilihat dari pola sebaran hotspot yang terpantau selama tahun 2010-2015. Pola sebaran hotspot mengikuti pergerakan manusia dalam memanfaatkan kawasan hutan dan lahan, baik secara legal maupun ilegal. Pemanfaatan secara legal adalah pemanfaatan kawasan hutan dan lahan negara melalui mekanisme perizinan dari pemerintah. Pemanfaatan lahan secara ilegal adalah pemanfaatan kawasan hutan dan lahan negara tanpa melalui mekanisme perizinan. Pemanfaatan hutan secara legal dapat berupa perhutanan sosial yang merupakan salah satu program nasional bertujuan untuk memberikan pemerataan ekonomi dan mengurangi ketimpangan ekonomi melalui tiga pilar, yaitu: lahan, kesempatan usaha dan sumberdaya manusia. Skema perhutanan sosial dapat berupa 1) Hutan Desa (HD), yaitu hutan negara yang pengelolaannya diberikan kepada lembaga desa untuk kesejahteraan desa, 2) Hutan Kemasyarakatan (HKm), yaitu hutan negara yang pemanfaatan utamanya untuk memberdayakan masyarakat setempat, 3) Hutan Tanaman Rakyat (HTR/IPHPS), yaitu hutan tanaman pada hutan produksi yang dibangun oleh kelompok masyarakat untuk meningkatkan potensi dan kualitas hutan produksi, 4) Hutan Adat (HA), yaitu hutan yang berada dalam wilayah masyarakat adat, dan 5) Kemitraan Kehutanan, yaitu adanya kerjasama antara masyarakat dengan pengelola hutan, pemegang Izin Usaha Pemanfaatan Hutan, dll. Sedangkan pemanfaatan hutan secara ilegal dapat berupa pemanfaatan kawasan hutan tanpa izin yang sah seperti penebangan liar (illegal logging) atau dengan izin yang sah namun tidak sesuai dengan ketentuan yang terdapat dalam perizinan.

\section{- Sebaran Hotspot Berdasarkan Administrasi Pemerintahan}

Sebaran hotspot berdasarkan administrasi wilayah pemerintahan menunjukan pola yang unik. Selama tahun 2010-2015 pola sebaran cenderung sama, yaitu berada pada wilayah pesisir timur Riau. Selama tahun 2005-2012, sebaran hotspot terbanyak terjadi pada tahun 2005 yang mencapai 1.571 titik hotspot (Kota Dumai) dan 1.404 titik hotspot (Kabupaten Bengkalis) serta 1.364 titik hotspot (Kabupaten Rokan Hilir).

Kejadian kebakaran hutan dan lahan tertinggi pada tahun 2005 terjadi di Kabupaten Bengkalis, Rokan Hilir dan Kota Dumai. Hal ini disebabkan oleh posisi yang berada di wilayah pesisir. Sebagian besar wilayah pesisir, ketika memasuki musim kemarau kondisinya akan menjadi kering dan rawan terjadi kebakaran hutan dan lahan. Hal ini diimbangi dengan kondisi curah hujan di daerah pesisir yang cenderung rendah. Cuaca kering dan hembusan angin menambah cakupan luas wilayah kebakaran serta menyulitkan proses pemadaman. Pihak BMKG menyampaikan 
bahwa potensi kejadian kebakaran hutan dan lahan di daerah pesisir Riau cukup tinggi, dikarenakan curah hujan yang sangat kecil dan cuaca yang cukup panas (Muhardi, 2019). Pembukaan lahan perkebunan skala kecil yang dilakukan oleh masyarakat pendatang turut berperan dalam kebakaran hutan dan lahan (Sigit, 2014). Selain itu, Riau merupakan daerah rawan terjadinya bencana kebakaran hutan dan lahan karena kondisi geografis yang sangat memungkinkan terjadinya kebakaran hutan dan lahan. Kondisi geografis yang mampu mendorong terjadinya kebakaran hutan dan lahan adalah dominasi lahan gambut seluas 5,7 ha atau 51,6 persen dari total gambut yang ada di Pulau Sumatera, cuaca ekstrim akibat curah hujan rendah dan suhu tinggi, adanya kanalisasi lahan gambut yang berlebihan, serta pola pemukiman dan pembukaan lahan pertanian yang dilakukan secara sporadis (Beritasatu.com, 2015).

Sebagai salah satu contoh adalah sebaran hotspot pada tahun 2010 menunjukkan bahwa jumlah hotspot sebagian besar berada di wilayah pesisir timur Riau. Hotspot yang terjadi pada tahun 2010 merupakan hotspot yang lebih kecil jumlahnya dibandingkan dengan tahun 2012 (Gambar 2). Sebaran hotspot tersebut berada di Kabupaten Rokan Hilir, Dumai dan Bengkalis. Peta sebaran hotspot tahun 2010 tertera pada Gambar 3.

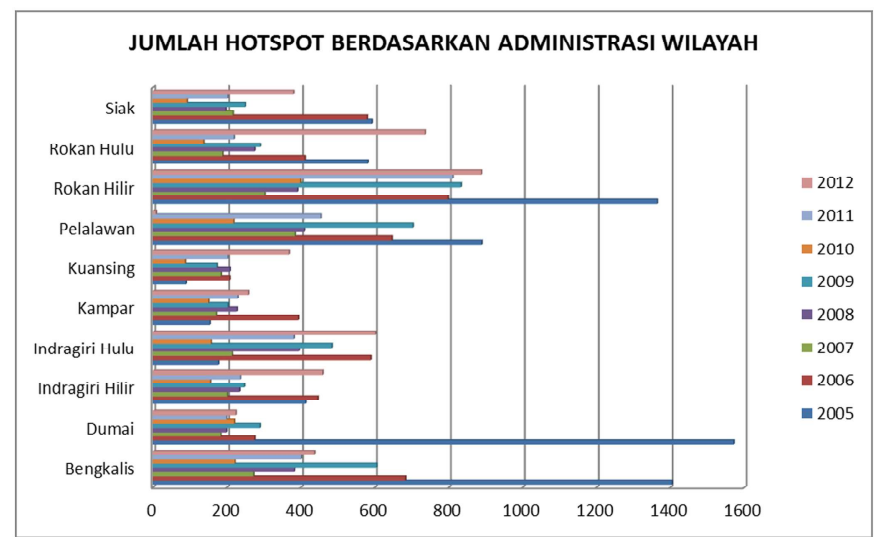

Sumber : Hasil analisis data (2015)

Gambar 2. Grafik kebakaran hutan dan lahan selama tahun 2005-2012

Figure 2. Chart of forest and land fires during 2005-2012

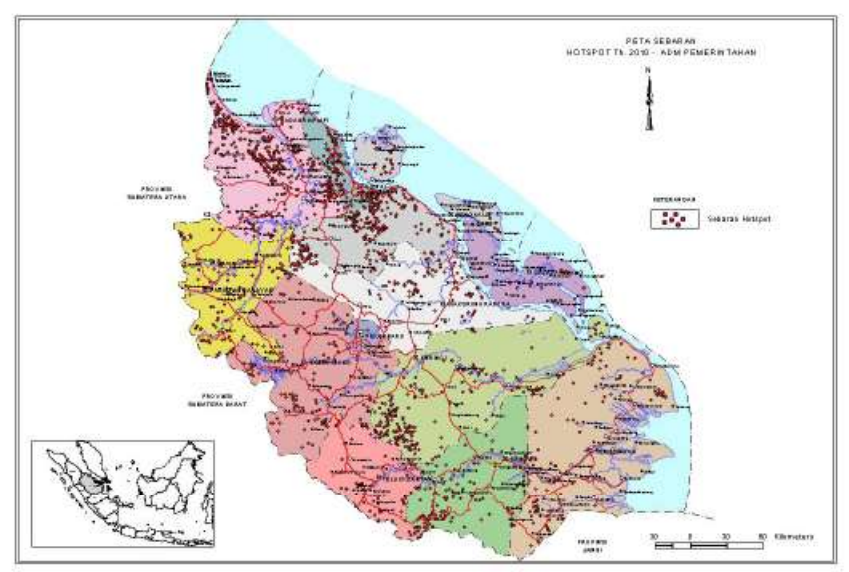

Gambar 3. Sebaran hotspot tahun 2010 berdasarkan administrasi wilayah Figure 3. Hotspots distribution in 2010 based on regional administration 


\section{- Sebaran Hotspot Berdasarkan Jenis} Tanah

Berdasarkan jenis tanah, sebagian besar hotspot berada di lahan mineral. Sebagaimana terlihat pada Gambar 4, hotspot di lahan gambut lebih banyak menyebar di daerah
Pesisir Timur Riau yaitu di Kabupaten Rokan Hilir, Dumai, Bengkalis dan Kepulauan Meranti. Sementara itu, hotspot yang berada di tanah mineral lebih banyak terlihat di Kabupaten Pelalawan, tepatnya di Taman Nasional Tesso Nilo.

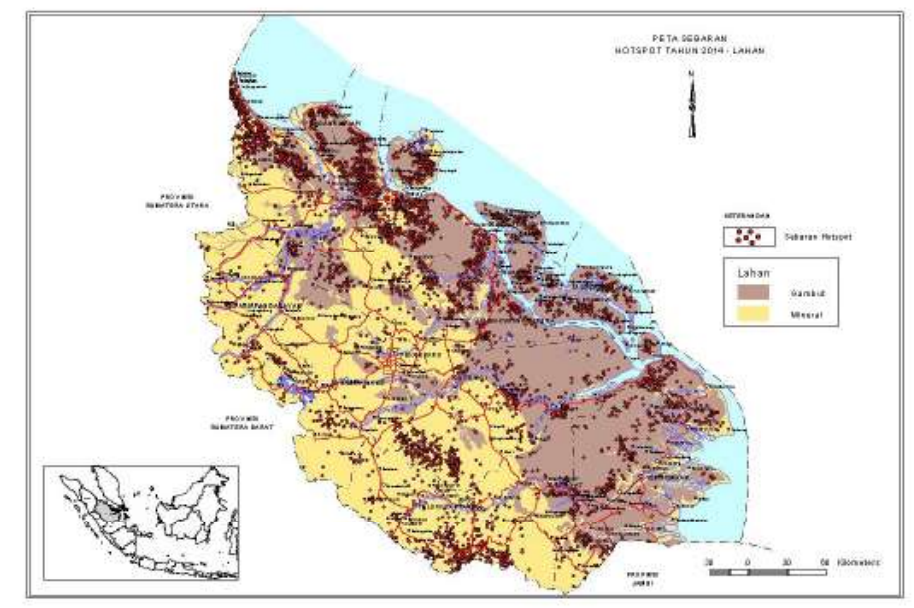

Gambar 4. Sebaran hotspot tahun 2014 berdasarkan jenis tanah Figure 4. Hotspots distribution in 2014 based on soil type

Ditinjau dari perjalanan waktu, sebaran jumlah hotspot terbesar selama tahun 20102015 terjadi pada tahun 2013 dan 2014 (Tabel 1).

Hotspot di tanah gambut dan mineral memiliki jumlah sebaran yang hampir sama. Walaupun demikian, dampak yang ditimbulkan oleh kebakaran yang terjadipada tanah gambut lebih besar dari tanah mineral. Kebakaran hutan dan lahan gambut merupakan kebakaran yang terjadi di atas permukaan (seresah, semak, pohon, dll) kemudian menyebar secara tidak menentu dan perlahan menuju ke bawah permukaan (ground fire) dan terjadi kebakaran bawah tanah, hanya asapnya saja yang muncul ke permukaan sehingga menyulitkan dalam proses pemadaman dan berdampak besar terhadap terdegradasinya kondisi lingkungan, sosial ekonomi serta kesehatan masyarakat.

\section{- Sebaran Hotspot Berdasarkan Tutupan Lahan}

Sebaran hotspot berdasarkan tutupan lahan berisi informasi mengenai tutupan hutan dan jumlah hotspot. Dalam kaitan ini, sebaran hotspot dapat dikelompokkan berdasarkan 17

Tabel 1. Sebaran Hotspot Berdasarkan Jenis Tanah

Table 1. Hotspots Distribution Based on Soil Type

\begin{tabular}{cccc}
\hline \multirow{2}{*}{ No } & \multirow{2}{*}{ Tahun } & \multicolumn{2}{c}{ Jumlah Hotspot } \\
\cline { 3 - 4 } & & Tanah Mineral & Tanah Gambut \\
\hline 1 & 2010 & 635 & 569 \\
2 & 2011 & 860 & 881 \\
3 & 2012 & 1355 & 1649 \\
4 & 2013 & 2051 & 1749 \\
5 & 2014 & 2104 & 1199 \\
6 & 2015 & 225 & 152 \\
\hline
\end{tabular}

Sumber : Hasil analisis data (2015) 
Tabel 2. Jumlah sebaran hotspot berdasarkan tutupan lahan

Table 2. Hotspot distribution number based on land cover

\begin{tabular}{rlrrrrr}
\hline & \multicolumn{1}{c}{ Tutupan Lahan } & \multicolumn{5}{c}{ Lahan } \\
\cline { 2 - 6 } No. & & 2010 & 2011 & 2012 & 2013 & 2014 \\
\hline 1 & Hutan lahan kering primer & 7 & 1 & 21 & 17 & 12 \\
2 & Hutan lahan kering sekunder & 79 & 112 & 172 & 144 & 93 \\
3 & Hutan mangrove sekunder & 2 & 1 & 2 & 4 & 7 \\
4 & Hutan rawa primer & 9 & 7 & 8 & 9 & 5 \\
5 & Hutan rawa sekunder & 214 & 226 & 274 & 394 & 356 \\
6 & Hutan tanaman industri & 124 & 209 & 536 & 525 & 345 \\
7 & Perkebunan & 138 & 270 & 451 & 602 & 445 \\
8 & Pemukiman & 1 & 1 & 1 & 2 & 2 \\
9 & Pertambangan & 3 & 11 & 6 & 15 & 6 \\
10 & Pertanian lahan kering & 12 & 24 & 30 & 31 & 18 \\
11 & Pertanian lahan kering campur & 78 & 145 & 202 & 638 & 499 \\
& semak & & & & & \\
12 & Rawa & 8 & 6 & 10 & 21 & 10 \\
13 & Sawah & 3 & 2 & 6 & 6 & 5 \\
14 & Semak belukar & 105 & 168 & 405 & 77 & 46 \\
15 & Semak belukar rawa & 277 & 387 & 658 & 954 & 860 \\
16 & Tanah terbuka & 142 & 173 & 222 & 370 & 600 \\
17 & Transmigrasi & 2 & & & & \\
\hline Sumber: Hasil analisis data (2015) & & & & &
\end{tabular}

jenis tutupan seperti tertera pada Tabel 2.

Tabel 2 menunjukkan bahwa hotspot terbanyak selama tahun 2010-2014 berada pada areal semak belukar rawa. Semak belukar rawa dapat diidentifikasikan sebagai kawasan hutan maupun non-hutan yang belum dimanfaatkan.

Hampir seluruh kebakaran hutan dan lahan terjadi pada kawasan hutan/lahan yang mengalami perubahan penutupan yang dilakukan manusia untuk memanfaatkan kawasan hutan/lahan tersebut. Tabel 2 memberikan informasi kebakaran hutan dan lahan terjadi pada hutan yang telah mengalami degradasi karena sebelumnya telah dimanfaatkan. Kebakaran hutan tidak terjadi pada hutan alam.

\section{- Sebaran Hotspot Berdasarkan Areal Pemanfaatan}

Pemetaan hotspot berdasarkan areal pemanfaatan ini dimaksudkan untuk mengetahui keterkaitan antara kebakaran hutan dan lahan dengan keberadaan pengelola kawasan hutan yang dimaksud. Data hasil overlay antara areal pemanfaatan dan sebaran hutan dan lahan dengan keberadaan pengelola kawasan hutan yang dimaksud. Data hasil overlay antara areal pemanfaatan dan sebaran hotspot yang terjadi selama tahun 2010-2015 akan menunjukkan kecenderungan dimana lokasi terjadinya kebakaran hutan dan lahan. Data tersebut tertera pada Tabel 3.

Tabel 3. Sebaran hotspot berdasarkan fungsi hutan Table 3. Hotspots distribution based on forest function

\begin{tabular}{ccrccccc}
\hline \multirow{2}{*}{ No } & \multirow{2}{*}{ Tahun } & \multicolumn{5}{c}{ Jumlah hotspot berdasarkan areal pemanfaatan } \\
\cline { 2 - 7 } & & APL1 & HL & HP & HK & HPT & KSA \\
\hline 1 & 2010 & 78 & 39 & 461 & 40 & 474 & 112 \\
2 & 2011 & 88 & 79 & 608 & 57 & 805 & 106
\end{tabular}


Lanjutan Tabel 3.

\begin{tabular}{rrrrrrrr}
3 & 2012 & 163 & 205 & 911 & 119 & 1336 & 270 \\
4 & 2013 & 191 & 211 & 1342 & 151 & 1561 & 343 \\
5 & 2014 & 176 & 147 & 1279 & 122 & 1329 & 257 \\
6 & 2015 & 18 & 14 & 96 & 10 & 175 & 64 \\
\hline
\end{tabular}

Sumber : Hasil analisis data (2015)

Keterangan:

$\mathrm{APL}=$ Areal Penggunaan Lain

$\mathrm{HL}=$ Hutan Lindung

$\mathrm{HP}=$ Hutan Produksi

$\mathrm{HK}=$ Hutan Konversi
HPT = Hutan Produksi Terbatas

$\mathrm{KSA}=$ Kawasan Suaka Alam
Tabel 3 menunjukkan bahwa dalam kurun waktu 2010-2015, jumlah hotspot terbanyak terjadi pada areal HPT (Hutan Produksi Terbatas). Sedangkan jumlah hotspotterendah terdapat pada areal hutan lindung. Hotspot banyak ditemukan di areal HPT dikarenakan salah satunya akibat kurangnya pengawasan baik dari pemilik ijin kelola kawasan maupun pemerintah. Kurangnya pengawasan berkaitan erat dengan kebakaran hutan dan lahan karena masyarakat dapat dengan leluasa masuk ke dalam kawasan untuk melakukan aktifitas seperti pembukaan lahan dengan cara membakar. Contohnya dapat dilihat pada kawasan TN Tesso Nillo yang sebelumnya merupakan areal HPT, Handoyo (2015) dalam tulisannya menyampaikan bahwa luasan kawasan yang digarap untuk keperluan lain di luar bidang kehutanan telah mencapai 52.244 ha, sebagian besar digunakan untuk pengembangan sawit.

\section{B. Faktor Penyebab Kebakaran Hutan dan Lahan}

Permasalahan kebakaran hutan dan lahan sangat kompleks dan disebabkan oleh beberapa faktor yang saling berhubungan.

Penyebab kebakaran hutan dan lahan di Riau dapat diketahui dari karakteristik inheren sumberdaya hutan dan lahan. Karakteristik tersebut mempengaruhi perilaku para aktor yang memiliki kepentingan terhadap sumberdaya hutan dan lahan (Agrawal dan Ostrom, 2008).

\section{Hubungan Kebakaran Hutan dan Lahan dengan Pemanfaatan Kawasan}

Hubungan kebakaran hutan dan lahan dengan pemanfaatan kawasan hutan dapat dibedakan menjadi kebakaran hutan lahan yang terjadi di kawasan konsesi Izin Usaha Pemanfaatan Hasil Hutan Kayu Hutan TanamanIndustri (IUPHHK-HTI), di areal perkebunan kelapa sawit, dan Areal Penggunaan Lain (APL).

Hotspot terbanyak selama tahun 20102015 terjadi pada tahun 2013 yaitu pada areal IUPHHK-HT. Hotspot terendah terdapat di dalam kawasan HGU perkebunan kelapa sawit (Tabel 4). Data yang dipetakan adalah data perkebunan yang memiliki HGU, sedangkan perkebunan rakyat yang tidak memiliki HGU tidak dimasukkan dalam pemetaan ini.

Tabel 4. Sebaran hotspot di beberapa areal pemanfaatan lahan tahun 2010-2015 Table 4. Hotspots distribution in several areas of land use in 2010-2015

\begin{tabular}{lcccc}
\hline \multirow{2}{*}{ No } & \multirow{2}{*}{ Tahun } & \multicolumn{3}{c}{ Jumlah Hotspot } \\
\cline { 3 - 5 } & & IUPHHK-HT & Perkebunan & APL \\
\hline 1. & 2010 & 649 & 83 & 476 \\
2. & 2011 & 1009 & 107 & 634 \\
3. & 2012 & 1705 & 174 & 1132 \\
4. & 2013 & 1961 & 214 & 1641 \\
5. & 2014 & 1792 & 177 & 1347 \\
6. & 2015 & 179 & 23 & 176 \\
\hline
\end{tabular}

Sumber : Hasil analisis data (2015) 
Areal IUPHHK-HT di Riau yang memiliki izin pemanfaatan kawasan hutan yaitu seluas 2.112.186 ha (Indriani, 2019), belum sepenuhnya dapat dikelola, karena banyaknya perambahan yang dilakukan oleh masyarakat. Masyarakat melakukan penguasaan lahan dengan tujuan untuk alih fungsi lahan menjadi perkebunan kelapa sawit. Pembukaan lahan dengan cara melakukan pembakaran hutan gambut yang sebagian besar merupakan areal lindung dari IUPHHK-HT. Areal lindung umumnya tidak dimanfaatkan oleh perusahaan karena merupakan areal tanaman kehidupan sehingga muncul perbedaan persepsi dari masyarakat yang menganggap bahwa areal tersebut tidak dikelola dan cenderung dibiarkan oleh perusahaan pemegang izin. Kegiatan pembakaran di areal lindung membahayakan areal tanaman pokok karena bunga-bunga api dapat terbawa oleh angin yang dapat membakar areal tanaman pokok.

Kebakaran hutan dan lahan yang terjadi di Indonesia pada umumnya dan di Riau pada khususnya sebagian besar disebabkan oleh aktivitas manusia. Banyak faktor yang mempengaruhi alasan masyarakat melakukan pembakaran lahan, salah satunya adalah faktor ekonomi.

Sangat sulit untuk menjumpai masyarakat yang diindikasikan sebagai aktor pembakar hutan dan lahan. Hal ini dikarenakanmayoritas aktor pembakar hutan dan lahan bukan merupakan masyarakat yang tinggal di dekat lokasi kebakaran hutan dan lahan. Bahkan, masyarakat setempat cenderung tidak mengetahui siapa yang melakukan di beberapa Kabupaten di Provinsi Riau, pembukaan lahan dilakukan oleh masyarakat dengan alasan berikut: 1) ingin membuat kebun kelapa sawit, 2) meningkatkan peluang dan nilai jual lahan open access. Pembakaran dilakukan untuk menyiapkan lahan dengan tujuan untuk usaha di bidang pertanian dan perkebunan. Pembukaan lahan secara besarbesaran dilakukan dengan cara membakar oleh masyarakat karena dianggap lebih efektif dan efisien. Di samping itu, harga jual lahan yang sudah dibersihkan dengan cara dibakar memberikan nilai jual lahan yang lebih tinggi dibandingkan dengan yang tidak dibersihkan.

Narasumber kunci yang merupakan tokoh masyarakat pada waktu penelitian lapangan juga membenarkan, bahwa masyarakat menganggap beberapa areal perijinan yang tidak dimanfaatkan oleh perusahaan IUPHHKHT merupakan lahan "tidak bertuan" sehingga mendorong masyarakat masuk ke areal tersebut dan mengolahnya menjadi kebun kelapa sawit untuk memenuhi kebutuhan perekonomian mereka.

\section{Hubungan Kebakaran Hutan dan Lahan dengan Pembangunan Wilayah}

Hubungan kebakaran hutan dan lahan dengan pembangunan wilayah dilihat dari tingkat keterbukaan wilayah (berdasarkan jaringan jalan) dengan sebaran hotspot yang ada. Jaringan jalan yang tinggi menunjukkan bahwa tingkat keterbukaan wilayah tersebut juga tinggi serta memiliki korelasi positif dengan pembangunan wilayah. Data sebaran hotspot berdasarkan jaringan jalan dapat dilihat pada Gambar 5.

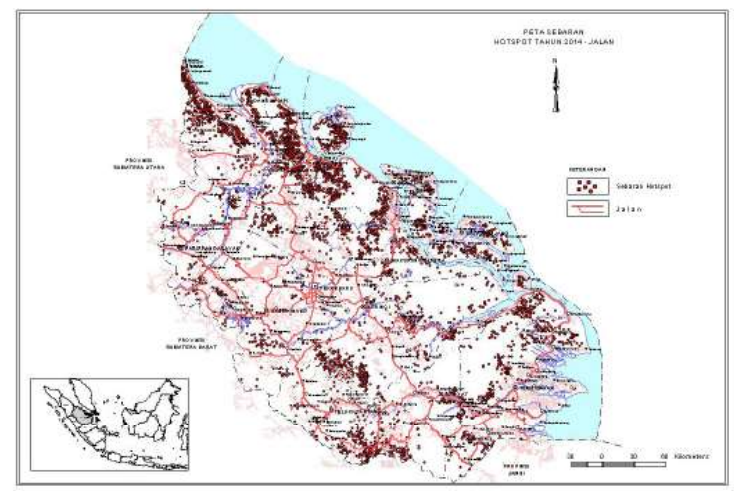

Gambar 5. Sebaran hotspot berdasarkan jaringan jalan

Figure 5. Hotspots distribution based on road networks 
Gambar 5 menunjukkan kebakaran hutan dan lahan terjadi pada wilayah yang sulit dijangkau, yaitu wilayah yang jauh dari jaringan jalan yang terpetakan (jalan utama). Kebakaran cenderung terjadi di wilayah pedalaman yang memiliki akses rendah. Implikasi dari informasi sebaran hotspot berdasarkan sebaran jaringan jalan ini memberikan sinyal bahwa kebakaran hutan dan lahan berada jauh dari pemukiman warga. Hal ini berhubungan dengan kepedulian masyarakat, dampak kebakaran dan pengawasan yang dapat dilakukan oleh masyarakat.

Masyarakat cenderung kurang peduli terhadap pendatang yang ada di lingkungannya sehingga ketika terjadi kebakaran hutan dan lahan. Petugas gabungan dari tim satgas dalkarhutla (satuan petugas pengendalian kebakaran hutan dan lahan) mengalami kesulitan mencari informasi terkait siapa pemilik lahan dan siapa yang menggarap lahan tersebut. Berdasarkan informasi yang disampaikan oleh narasumber kunci yang merupakan seorang perangkat desa di Kabupaten Bengkalis, kepemilikan lahan (biasanya berupa perkebunan sawit) sebagian besar bukan merupakan masyarakat desa sekitar, tetapi berasal dari kota Pekanbaru hingga Jakarta. Pembukaan lahan baru untuk perkebunan kelapa sawit mengakibatkan munculnya jaringan jalan baru. Tersedianya akses masuk tersebut mempermudah masyarakat masuk ke dalam kawasan sehingga mengakibatkan adanya pembukaan lahan baru yang berdampak pada kejadian kebakaran hutan dan lahan. Selain itu, hanya sebagian kecil masyarakat yang pernah mengikuti sosialisasi penanggulangan kebakaran hutan dan lahan. Perlu dilakukan sosialisasi dan pelatihan bagi masyarakat sehingga mengetahui apa yang harus dilakukan ketika terjadi kebakaran hutan dan lahan di wilayahnya terutama yang berada jauh dari wilayah pemukiman.

\section{Hubungan Kebakaran Hutan dan Lahan dengan Politik Lokal}

Hubungan antara kebakaran hutan dan lahan dengan kondisi politik lokal dilihat dari jumlah hotspot dengan aktifitas politik lokal yang terjadi pada tingkat kabupaten/kota atau desa. Hubungan antara hotspot dengan kondisi politik lokal ini tidak terjadi secara langsung. Hotspot yang ada merupakan hasil dari pembukaan hutan maupun lahan untuk dijadikan perkebunan kelapa sawit. Sementara itu, pembukaan hutan dan lahan sebagian besar berhubungan dengan tindakan okupasi kawasan hutan. Okupasi yang dimaksud adalah pendudukan/penguasaan lahan hutan yang belum dikelola ataupun yang sudah dikelola, yang dilakukan oleh masyarakat secara ilegal. Keterkaitan antara kebakaran hutan dan lahan dengan kegiatan politik lokal tersebut dilihat dari 2 kondisi, yaitu: a. Keterkaitan jumlah hotspot dengan kegiatan politik pemilihan kepala daerah atau pemilihan kepala desa.

Keterkaitan jumlah hotspot dengan pemilihan kepala daerah (Bupati) maupun kepala desa dapat dilihat pada kasus kebakaran hutan dan lahan yang terjadi di Taman Nasional Tesso Nilo. Pemekaran wilayah desa Air Hitam yang berada di wilayah administrasi Kabupaten Pelalawan menyebabkan tingginya frekuensi kebakaran hutan dan lahan. Hal tersebut disebabkan adanya migrasi penduduk dari luar wilayah Riau yang masuk ke dalam Desa Air Hitam. Berdasarkan informasi yang disampaikan oleh narasumber kunci yang merupakan tokoh adat di salah satu desa yang berada di dalam kawasan hutan Tesso Nilo pada tahun 2015, migrasi penduduk sengaja dilakukan untuk memenangkan salah satu calon tertentu dalam pemilihan kepala desa. Masyarakat yang didatangkan tersebut dijanjikan memperoleh areal perkebunan kelapa sawit melalui pembelian dari pihak tertentu. Pembukaan areal dilakukan oleh masyarakat dengan cara membakar areal hutan, karena dinilai lebih efektif dan efisien karena tidak memerlukan banyak biaya dan tenaga.

Purnomo et al., 2016 menyampaikan hasil pengamatannya, ditemukan bahwa ada koneksi yang kuat antara Pilkada 
(Pemilihan Kepala Daerah) di Sumatera dan Kalimantan dengan hotspot (titik api), seperti digambarkan pada Tabel 5. b. Jaringan Aktor dan Kekuasaan

Keterkaitan politik dengan kebakaran hutan dan lahan dapat dilihat dari pola

Tabel 5. Hubungan antara pilkada dan jumlah titik api

Table 5. Relationship between the election and hotspots number

\begin{tabular}{lccl}
\hline No & Tahun & Jumlah Hotspot & \multicolumn{1}{l}{ Keterangan } \\
\hline 1 & $2000-2002$ & $<5.000$ & \\
\hline 2 & 2003 & \pm 10.000 & Pemilihan Presiden \\
\hline 3 & 2004 & \pm 20.000 & $\begin{array}{l}\text { Indragiri Hulu, Bengkalis, } \\
\text { Dumai }\end{array}$ \\
\hline 5 & 2005 & \pm 15.000 & $\begin{array}{l}\text { Pelalawan, Rokan Hulu, } \\
\text { Kuantan Singingi, Rokan } \\
\text { Hilir, Siak, Pekanbaru, } \\
\text { Kampar }\end{array}$ \\
\hline 6 & 2006 & \pm 30.000 & Indragiri Hilir, Riau \\
\hline 7 & 2009 & \pm 20.000 & $\begin{array}{l}\text { Pemilihan Kepala Daerah } \\
\text { serempak }\end{array}$ \\
\hline 8 & 2014 & \pm 10.000 & $\begin{array}{l}\text { Pemilihan Kepala Daerah } \\
\text { serempak }\end{array}$ \\
\hline 9 & 2015 & \pm 25.000 &
\end{tabular}

Sumber : (Agustinus, 2016)

hubungan antar aktor yang membentuk suatu jaringan. Keterkaitan ini secara tidak langsung memengaruhi kebakaran hutan dan lahan. Aktor dan hubungan aktor yang menyebabkan terjadinya kebakaran hutan dan lahan dapat dibedakan menjadi 3 tingkatan didasarkan pada wilayah administratif, yaitu:

\section{- Tingkat Desa}

Aktor yang terlibat di tingkat desa adalah tokoh adat/ninik-mamak, masyarakat asli dan pendatang serta tokoh desa. Masingmasing aktor ini memiliki keterkaitan serta peran tersendiri dalam proses okupasi areal hutan. Hasil penelusuran melalui wawancara mendalam dengan informan kunci diketahui bahwa terdapat beberapa oknum ninikmamak yang merampas tanah ulayat dengan curang bekerjasama dengan pihak lain untuk mendapatkan keuntungan pribadi, salah satu kasusnya terjadi di Kabupaten Kampar. Padahal, tanah ulayat merupakan warisan leluhur yang diperuntukkan untuk anak cucu kemenakan. Tanah ulayat yang sudah dibagibagi luasannya kemudian diperjual-belikan kepada masyarakat pendatang.
Sedangkan untuk proses pengurusan administrasi tanah, pihak ninik-mamak dan pembeli/masyarakat pendatang bekerja sama dengan oknum pihak desa setempat. Purnomo et al., 2015b dalam penelitiannya menyebutkan lahan yang diperjualbelikan didukung dengan dokumen pendukung kepemilikan yang dikeluarkan oleh pemerintah desa untuk meyakinkan calon pembeli dengan mengeluarkan surat blok, SKT (Surat Keterangan Tanah) dan SKGR (Surat Keterangan Ganti Rugi).

- Tingkat Kecamatan

Aktor yang terlibat di tingkat kecamatan adalah tokoh kecamatan/perangkat kecamatan. Keterlibatan oknum pihak kecamatan merupakan keberlanjutan proses dari oknum pihak desa dalam penerbitan administrasi tanah. SKGR yang diloloskan oleh pihak kecamatan memiliki nilai lebih jika ditandatangani oleh camat.

- Tingkat Kabupaten

Aktor yang terlibat di tingkat kabupaten adalah oknum Badan Pertanahan Nasional 
(BPN) dan oknum tokoh di tingkat Pemerintah Daerah yang saling memiliki keterikatan. Keterlibatan oknum di tingkat kabupaten merupakan keberlanjutan dari proses di tingkat kecamatan. Berdasarkan data yang diperoleh mengungkapkan bahwa pada tahun 2017 terdapat penindakan hukum dugaan tipikor (tindak pidana korupsi) terkait penerbitan Surat Hak Milik (SHM) di kawasan hutan Taman Nasional Tesso Nilo terhadap 5 orang tersangka oknum BPN (Yafiz, 2017).

Penjelasan keterkaitan kebakaran hutan dan lahan dengan politik lokal diperkuat dengan hasil penelitian yang dilakukan oleh Purnomo et al., 2015a yang menyebutkan bahwa pilkada atau pemilihan elit politik lokal sering melibatkan transaksi lahan dengan memberikan akses pada penduduk atau migran untuk mengelola lahan seperti yang terjadi di beberapa daerah di Riau. Lahan yang diberikan akses biasanya merupakan lahan atau hutan yang berstatus "open access" baik di kawasan hutan maupun konsesi. Kasus kebakaran hutan dan lahan yang dapat menjelaskan jaringan aktor dalam proses kejadian kebakaran hutan dan lahan terjadi di Taman Nasional Tesso Nilo yang sudah terstruktur dan berjalan sejak lama.

\section{KESIMPULAN}

Berdasarkan hasil overlay diperoleh bahwa kejadian kebakaran hutan dan lahan terbanyak terjadi di wilayah pesisir timur Provinsi Riau, yaitu di Kabupaten Rokan Hilir, Bengkalis, Siak, Kepulauan Meranti dan Pelalawan. Beberapa penyebab kebakaran hutan dan lahan adalah akibat pemanfaatan kawasan yang belum dikelola secara optimal, pembukaan akses jalan baru untuk pembangunan seperti pembuatan kebun baru, dan politik lokal atau pemilihan kepala daerah.

\section{SARAN DAN REKOMENDASI}

Pemerintah perlu meningkatkan kewaspadaan tinggi di areal yang berpotensi terjadi konflik pemanfaatan kawasan hutan antara masyarakat dengan perusahaan seperti di areal izin konsesi IUPHHK-HTI. Kewaspadaan perlu dilakukan dengan memperjelas status kawasan di areal konflik dengan memberikan kepastian hukum terhadap suatu kawasan melalui pengukuhan kawasan hutan agar legal dan legitimate. Diperlukan penyelesaian kasus konflik pemanfaatan sumberdaya hutan dengan menerapkan prinsip win-win solution bagi pihak yang berkonflik.

\section{UCAPAN TERIMAKASIH}

Terimakasih diucapkan kepada Kementerian Lingkungan Hidup dan Kehutanan (KLHK), Badan Litbang dan Inovasi KLHK, BP2TSTH Kuok, tim penelitian Resolusi Konflik BP2TSTH Kuok, narasumber serta pihak lain yang tidak dapat disebutkan satu per satu.

\section{DAFTAR PUSTAKA}

Agrawal, A., \& Ostrom, E. (2008). Decentralization and community-based forestry: learning from experience. Decentralization, forests and rural communities: Policy outcomes in South and Southeast Asia, 44-67.

Agustinus, M. (2016). Temuan Baru Ada Hubungan Kebakaran Lahan Gambut dengan Pilkada. detikFinance. https:// finance.detik.com/industri/d-3278276/ temuan-baru-ada-hubungan-kebakaranlahan-gambut-dengan-pilkada

Baqiroh, N. F. A. B. (2019). Konflik Tenurial Dinilai Bisa Picu Kebakaran Hutan dan Lahan-Ekonomi Bisnis. Bisnis. com.https://ekonomi.bisnis.com/ $\mathrm{read} / 20190703 / 99 / 1119453 /$ konfliktenurial-dinilai-bisa-picu-kebakaranhutan-dan-lahan

BBCNews.com. (2015). Kebakaran hutan dan lahan Indonesia bisa samai insiden 1997-BBC News Indonesia. BBCnews.com. https://www.bbc.com/indonesia/berita_ indonesia/2015/10/151002_indonesia_ asap_rekor

Beritasatu. (2015). Ratusan Desa di Riau Rawan Kebakaran Hutan - BeritaSatu. Beritasatu.com. https://www. beritasatu. com/kesra/271503-ratusan-desa-di-riaurawan-kebakaran-hutan.html

Handoyo. (2015). Resolusi Konflik di Taman Nasional Tesso Nilo Riau, Indonesia: Tinjauan Relasi Pemangku Kepentingan. Jurnal Analisis Kebijakan Kehutanan, Vol 12 No., 89-103. 
Indriani, D. (2019). Refleksi 2018 dan Harapan 2019 Menuju Keadilan Ekologis di Provinsi Riau. In Wahana Lingkungan Hidup Indonesia Eksekutif Daerah Riau - WALHI Riau.

Muhardi, F. (2019). Hujan minim, pesisir Riau rawan karhutla - ANTARA News. Antaranews. https://www.antaranews. com/berita/783502/hujan-minim-pesisirriau-rawan-karhutla

Purnamasari, D. M. (2019). BNPB : 80 Persen Lahan Terbakar Berubah Jadi Lahan Perkebunan. Kompas. com. https://nasional.kompas.com/ read/2019/09/18/09532771/bnpb-80persen-lahan-terbakar-berubah-jadilahan-perkebunan

Purnomo, H., Okarda, B., Shantiko, B., Achdiawan, R., Kartodiharjo, H., \& Dewayani, A. A. (2015a). Kabut Asap, Penggunaan Lahan dan Politik Lokal. Diskusi Pakar Kebakaran Hutan Dan Lahan Dan Bencana Asap Di Provinsi Jambi, February 2016.

Purnomo, H., Shantiko, B., Sitorus, S., \& Achdiawan, R. (2015b). Ekonomi Politik Kebakaran Hutan dan Lahan: Sebuah pendekatan analitis. Conference Paper, February 2016.

Purnomo, H., Shantiko, B., \& Gunawan, $\mathrm{H}$. (2016). Peat Fire Economy And Actor Network in Sumatera: An Analytical Approach. In Proceedings of the 15th International Peat Congress (Vol 1 of 2).

Setyawan, W. E. (2019). Menyibak Problem Kebakaran Hutan dan Lahan yang Tak Kunjung Usai. Mongabay. https://www. mongabay.co.id/2019/10/26/menyibakproblem-kebakaran-hutan-dan-lahan-diindonesia-yang-tak-pernah-usai/

Sigit, R. R. (2014). Perkebunan Sawit di Riau, Menyejahterakan Siapa? Mongabay. https://www.mongabay. co.id/2014/06/05/perkebunan-sawit-diriau-menyejahterakan-siapa/

Wulan, Y. C., Yasmi, Y., Purba, C., \& Wollenberg, E. (2004). Analisa Konflik Sektor Kehutanan di Indonesia 1997 - 2003. Center for International Forestry Research.

Yafiz, I. (2017). Kejati Lakukan Tahap II Terhadap Tersangka Tipikor Penerbitan Sertifikat di TNTN - Tribun Pekanbaru. Tribun Pekanbaru.com. https://pekanbaru. tribunnews.com/2017/09/19/kejatilakukan-tahap-ii-terhadap-tersangkatipikor-penerbitan-sertifikat-di-tntn 